\title{
Tools help patients tackle tough choices for end-of-life care
}

$\mathrm{T}$ he notion of advance care planning can be intimidating. Fraught with concern over their mortality and often confused by complex legal forms and checklists of unfamiliar medical procedures, many people feel overwhelmed by the process or are unable to envision the consequences of the tough decisions it entails.

An increasing number of tools, however, are helping patients break down the more challenging aspects of the process, such as expressing wishes for care, choosing a substitute decision maker or deciding where to draw the line on life-sustaining treatment.

Among those tools are workbooks developed by the Fraser Valley health region in British Columbia and the former Calgary health region in Alberta, which now serve as a sort of standardized form for creating legal advance directives, as well as a means by which patients can work out and articulate more general values, beliefs and wishes for care.

The My Voice workbooks - which can be downloaded from the Fraser Health Authority and Alberta Health Services websites (www.fraserhealth.ca /media/MyVoiceWorkbookENG.pdf and www.calgaryhealthregion.ca/programs /advancecareplanning/acp_docs/103284 _workbook_standard.pdf) — include a questionnaire designed to help patients parse through their hopes and fears about end-of-life. It also provides them an opportunity to define any spiritual or cultural considerations that might impact the type of care they would wish to receive.

"It's about moving from the science of medicine - the forms, the checklists of interventions - to the art of medicine," says Bert Enns, Calgaryregion project manager for Alberta Health Services.

The workbooks ask patients what they worry about when they think of death, what messages they would like to be remembered by and what simple pleasures - such as fresh air or spending

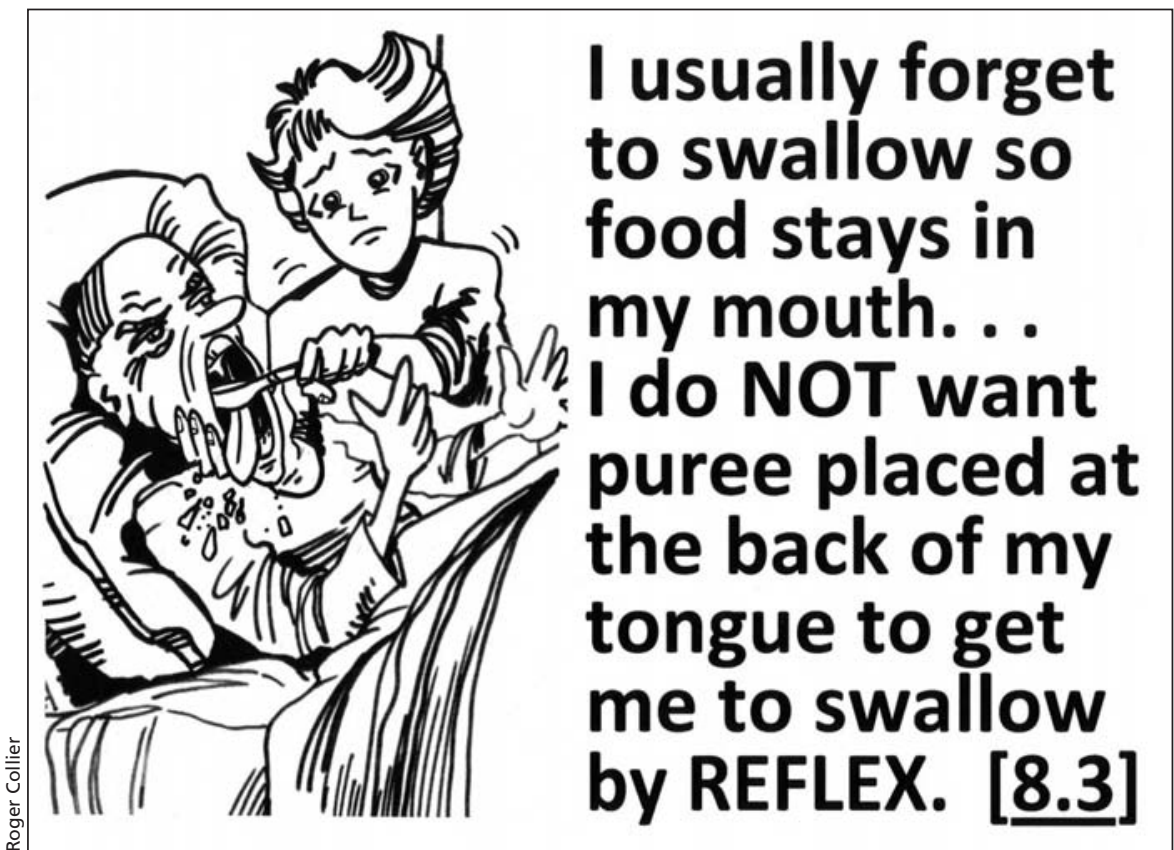

One of 47 "My Way Cards" developed a California company to help patients resolve the difficult dilemna of when to stop life-sustaining treatments and allow the natural dying process, with comfort care, to begin.

time with family - make life meaningful. It's a bid to provide substitute decision makers with a bigger picture of the patient's ideal quality of life and death than most instructional directives offer.

That context is "critically important" when it comes time for caregivers to follow through on either a 'Do Not Resuscitate' order or a patient's wish to receive all lifesustaining treatment possible, says Dr. Eric Wasylenko, executive director of clinical ethics for Alberta Health Services. Unlike instructional directives, expressions of wishes and beliefs "don't compel or restrict, but guide us to what the patient wants. It's better information at the complex time when someone has to make a tough decision and live with it."

The Calgary regional authority, which was dissolved when Alberta amalgamated its health divisions into a superboard, also developed a My Voice video to address common misconceptions about advance care planning and explain its importance at any age from a patient perspective (www.screencast.com/users /AHS.TH.MH/folders/chr/media/608b6 940-1d4a-49a8-86a6-4b9e1fc71f9c).

"People still jump to the conclusion that there's some other hidden message when health care providers bring up the conversation," says Wasylenko.

For that reason, many people end up turning to their lawyers when planning for end-of-life care, says Charles Sabatino, director of the American Bar Association's commission on law and aging. "People are already in a planning mode when they see an estate planner or attorney."

But while most lawyers are able to "find the appropriate legal form and execute it," Sabatino says few have the skills, training or time to "help people think through the issues and provide the counselling most useful in advance care planning."

In 2000, the American Bar Association developed a take-home toolkit for lawyers to give to clients considering advance care planning (www.abanet.org /aging/toolkit/). Among the suite of 
tools is a checklist of attributes to consider when naming a substitute decision maker or proxy, such as the ability to handle conflict between family members, friends and medical personnel.

"People, then and now, kind of assume the person closest to them for example, their spouse or partner will automatically be the best proxy, but that's not always the case," says Sabatino. "We wanted to provoke people to think about the criteria for a good proxy: someone who can act on your wishes, separate their own needs and wants from yours and who can stand up for you in a health care system that can be very controlling and not necessarily responsive to individual requests."

While numerous tools exist to help patients identify the kind of care and medical interventions they want to receive at end-of-life, few focus the person that will actually carry out those wishes, he adds.

The checklist is also accompanied by a "job description" for the proxy and a quiz to test their comprehension of the patient's wishes.

"Having someone who can do the job right is the most important aspect of advance care planning, but the job is usually dropped on their lap at a very difficult time with very little guidance," explains Sabatino. "I can't say how many times I've heard the story where a parent names their adult child as their proxy and says, 'You know what I want,' when in reality they don't have a clue."

The quiz requires a patient and their proxy to fill out 10 questions about the kind of care the patient would wish to receive should they be rendered incapable of making their own decisions, such as whether they would wish to receive aggressive antibiotic treatment for pneumonia. The patient can then compare their answers with their proxy's to see how well they've communicated their wishes.

"In truth, it's almost impossible to get the same answers. It's not as much a validated, standardized quiz as it is a tool to promote discussion," Sabatino says. "I've done this a few times as a macabre kind of parlour game among friends and it's always amazing to discover that people I thought would not want to keep aggressive treatment going in certain situations actually wanted to pull out all the stops right up to the end."

While many people are eager to discuss advance care planning, few feel comfortable bringing it up with family or friends for fear of upsetting them, he says.

A series of scripts is included in the toolkit to help patients broach the subject with their loved ones and answer some of the most common questions or concerns that the conversation invariably raises. The tool advises the patient to start off slow with a story of someone else's experience and even suggests blaming their attorney, should the topic be met with resistance.

While the toolkit was most recently updated in 2005, Sabatino says he'd like to review it again, particularly one tool which helps patients determine which symptoms or limitations of advanced illness they consider "worse than death."

The tool allows patients to rate on a scale of one to five how likely they would want to continue life-sustaining treatments if faced with certain conditions at end-of-life.

"Disability groups complained it promotes people's prejudices and research has shown people are willing to redraw the line on life-sustaining treatment when they're actually faced with these conditions, compared to when they're healthy and are just imagining them," Sabatino explains. "It really highlights the danger of including these kinds of things in a binding document, rather than in a workbook or just talking about them with loved ones."

However, it's an approach that's gaining popularity among patients who want to know what symptoms or conditions they might encounter near end-oflife before they decide on the level of care they would like to receive.
Among the aids to promote consideration of such symptoms is a deck of cards developed by a Carlsbad, California company that illustrates the losses of function and behaviours associated with the final stages of advanced dementia and other terminal illnesses to serve as a decision-making aid for patients.

Patients sort the 47 "My Way Cards" used by Caring Advocates one at a time to answer the difficult (and often deferred) question that lies at the heart of all advance care planning: when should one stop life-sustaining treatments and allow the natural dying process, with comfort care, to begin? The cards, which can be ordered for a fee, are used in used as part of inpatient advance care planning counselling (http://caringadvocates.org /MyWayCards/).

"One person who's very modest might say being incontinent and forced to have someone change their diapers is too much of an indignity and is a sign it's their time to go," says Dr. Stanley Terman, medical director of Caring Advocates. "Another person might find it a minor inconvenience but feel if they can still recognize their family then it's no big deal."

Faced with a list of medical interventions, patients often err on the side of prolonging life for fear of being denied treatment, even when the interventions they choose may speed or worsen their decline, Terman adds.

While Sabatino has "great doubts" about the symptom-based approach to advance care planning, he agrees that most healthy people have "no clue" what end-of-life looks like until they're staring it in the face. "I think more information is always useful, but it needs to be put into the context that in pretty dire situations most people can still have a meaningful relationship with the world around them and, just like healthy people, can still change their mind." - Lauren Vogel, CMAJ

CMAJ 2011.DOI:10.1503/cmaj.109-3750 